\title{
ISIS DAN STIGMA ISLAMOFOBIA FRAMING TENTANG KONSTRUKSI PEMBERITAAN ISIS DALAM MEDIA ONLINE
}

\author{
Isis and Islamophobia Stigma: \\ A Framing on Isis News Construction In The Online Media
}

\author{
Astinana Yuliarti ${ }^{1}$, M. Tahir Kasnawi ${ }^{2}$, Hafied Cangara ${ }^{3}$ \\ ${ }^{1}$ Ilmu Komunikasi, Fakultas Ilmu Sosial dan Ilmu Politik, Universitas Hasanuddin, \\ (Email: asma_aulia89@yahoo.com) \\ ${ }^{2}$ Sosiologi, Fakultas Ilmu Sosial dan Ilmu Politik, Universitas Hasanuddin, \\ (Email: hirka_unhas@yahoo.com \\ ${ }^{3}$ Ilmu Komunikasi, Fakultas Ilmu Sosial dan Ilmu Politik, Universitas Hasanuddin \\ (Email: cangara_hafied@yahoo.com)
}

\begin{abstract}
ABSTRAK
ISIS menjadi salah satu isu yang sering diangkat oleh berbagai media online. Tujuan penelitian ini adalah Menganalisis bagaimana media online mengkonstruksi dan memframing pemberitaan ISIS dalam membentuk stigma Islamofobia di masyarakat. Pendekatan yang digunakan dalam penelitian ini adalah analisis framing model Zhandong dan Gerald Kosicki dengan tipe penelitian analisis kualitatif. Data dalam penelitian ini berupa teks berita ISIS, baik berupa teks, foto maupun gambar dalam portal online Al Jazeera.com, CNN.com, Kompas.com, dan Republika.co.id. Hasil penelitian menunjukkan media online Al Jazeera.com, CNN.com, Kompas.com, dan Republika.co.id telah memberikan porsi terhadap pemberitaan ISIS dalam berkontribusi terhadap terbentuknya stigma Islamofobia (Anti-Muslim) di masyarakat. Dari hasil penelitian, CNN.com sebagai sebuah media barat kelihatan jelas memberikan porsi pemberitaan yang besar terkait ISIS. Lewat struktur sintaksis dan Retoris media ini, diperoleh gambaran adanya penekanan pemberitaan antara Muslim versus non-Muslim. AlJazeera, sendiri dalam melakukan framing berita ISIS memakai kacamata normatif. Bagaimana Muslim memperoleh imbas yang besar terhadap berbagai pemberitaan yang mengaitkan Islam dan ISIS, sementara media lokal Kompas.com melakukan framing berita berimbang walau pada kenyataan artikel yang dimuat dalam portal tersebut masih mengandung opini. Sedangkan, Portal Republika.co.id, jelas sekali dalam pemberitaanya menggambarkan anti- Amerika dan dunia barat. Republika mengemas berita dengan mengkonstruksinya sehingga pembaca akan terpengaruh bahwa Barat memiliki kebencian kepada Muslim karena agama mereka.
\end{abstract}

kata kunci: Framing, ISIS, Islamofobia, Media Online

\begin{abstract}
ISIS is one of the issues often raised by various online media. The purpose of this study is to analyze how online media construct and framing the news ISIS in shaping the stigma of Islamophobia in society. The approach used in this research is the analysis of framing and Gerald Kosicki Zhandong models with the type of qualitative analysis research. The data in this study of the text online news portal Al Jazeera.com, CNN.com, Kompas.com, and Republika.co.id related to news ISIS, either in the form of text, photos and drawings. The results showed online media Al Jazeera.com, CNN.com, Kompas.com, and Republika.co.id have given to the preaching portion ISIS in contributing to the formation of stigma Islamophobia (anti-Muslim) in the community. From the research, CNN.com as an apparent western media gives a large portion of news related to ISIS. Syntactic structures and Rhetorical through this medium we can see how the emphasis the news from the standpoint that American Muslims in contrast
\end{abstract}


to non-Muslims. AlJazeera, alone in doing framing news normative ISIS wearing glasses. How do Muslims gain a great impact on a variety of reports that linked Islam and ISIS. Local media like Kompas.com do the framing story with a more balanced despite the fact article published in the portal still contain opinions. Meanwhile, Republika.co.id Portal, is clear in pemberitaanya describe anti-American and the western world. Republika packed news to construct so that the reader will be distracted that the West has a hatred for Muslims because of their religion.

Keywords: Framing, ISIS, Islamophobia, Online Media

\section{PENDAHULUAN}

Media memiliki sifat atau karakteristik yang mampu menjangkau massa dalam jumlah besar dan luas (universality of reach), bersifat publik dan mampu memberikan popularitas kepada siapa saja yang muncul di media massa (McQuail, 2000).

Sejak kemajuan teknologi, perkembangan media massa dan komunikasi mengalami banyak perubahan. Media terus berkembang seiring perkembangan jaman, media makin berkembang pesat dengan munculnya internet. Tonggak awal kelahiran media dengan memanfaatkan internet terjadi pada tahun 1990. Tim Berners Lee menemukan program editor dan browser yang bisa menjelajah antara satu komputer dengan komputer yang lainnya, yang membentuk jaringan yang disebut World Wide Web atau yang biasanya disingkat dengan www. Pertumbuhan web sebagai media online semakin meningkat pesat. Terdapat dua faktor yang mempengaruhi mengapa web melonjak tinggi. Pertama, dikarenakan teknologi dan infrastruktur sudah menyebar dalam jumlah besar di masyarakat khususnya telepon dan komputer. Kedua, web juga multifungsi dan internet juga mempunyai fungsi yang meluas dan mudah diakses oleh seluruh orang didunia yang sudah memiliki sambungan internet.

Fakta menunjukkan bahwa dengan semakin berkembangnya teknologi maka seiring dengan semakin mudahnya masyarakat dalam berinteraksi. Hal inilah yang kemudian banyak digunakan oleh Media online menyampaikan pesan secara cepat dan mampu memperngaruhi masyarakat. Berbagai peristiwa kemudian dibingkai media online kemudian dengan berbagai angle kemudian disampaikan secara cepat sebagai sebuah kebutuhan kepada masyarakat. Fenomena yang berkembang saat ini jika dikaitkan dengan maraknya informasi yang berada disekitar masyarakat adalah salah satunya dengan meningkatnya semangat keagamaan di berbagai dunia. Informasi yang berkembang dengan portal online sebagai salah satau perantaranya mengabarkan kepada kita bahwa semangat keagamaan di berbagai negara telah diwarnai dengan sikap berlebihaan dan ekstrem (Mulkan, 2011).

Berbagai aksi kekerasan dan terorisme kini melekat di agama Islam. Tuduhan terhadap agama Islam sebagai agama yang menganjurkan kekerasan dan terorisme selalu terdengar. Berbagai berita-berita di berbagai media ramai memberitakan hal tersebut. Berita yang akhirakhir ini ramai diberitakan yaitu gerakan ISIS. Suatu fenomena saat ini yang menjadi trending topik berbagai media, khususnya media online.

Berita fenomena gerakan ISIS adalah suatu berita terkait dengan kelompok yang lahir di Irak dan Suriah. ISIS adalah singkatan Islamic State of Irak and Syria lahir pada tahun 2013 dengan ketua Abu Bakar al-Baghdadi. Sepak terjang ISIS di Irak dan Suriah banyak diberitakan. Kelompok yang awalnya ciptaan Al-Qaeda itu tampil sebagai gerakan yang amat sadis dan banyak melakukan tindakan di luar kemanusiaan. Kelompok ini dikenal dengan cara-cara kekerasan, pembunuhan, pemaksaan kehendak, menghancurkan tempat-tempat yang dianggap suci oleh umat Islam, merampok, menarik pajak. Kelompok ini bercirikan bendera hitam dengan kalimat tauhid sebagai lambang (Mubarak, 2015).

Media online yang merupakan bagian dari media massa telah berhasil menggiring pandangan masyarakat dan membentuk opini tersendiri tentang gerakan ISIS dengan berbagai setting yang dilakukan. Pemberitaan berkaitan dengan kekerasan, pemboman, penculikan dan lain sebagainya menjadi hal lumrah kini jika 
dikaitkan dengan aktivitas muslim radikal (garis keras) (Mubarok \& Made, 2012). Islam selalu menjadi tersangka dalam berbagai serangan terror di berbagai daerah di Indonesia bahkan di luar negeri. 13 November 2015, terjadi peristiwa yang mengagetkan dunia internasional, terjadi di jantung kota paris, perancis. Berbagai asumsi kemudian bermunculan, sehari setelah peristiwa bom dan tembakan yang terjadi kota Paris, Presiden Perancis Francois Hollande menyebutkan bahwa serangan teroris yang sedikitnya membunuh 127 orang, Jumat malam tersebut, sebagai perang yang dilakukan oleh kelompok militan Negara Islam Irak dan Suriah (ISIS) (Susilo, 2015).

Saat ini, Islamofobia muncul dari berbagai kalangan, termasuk dari kalangan menengah keatas. Mulai dari mereka yang mencela maupun yang mengkritik Islam (Sheehi, 2011). Islamofobia, ditunjukkan dari setiap kalangan dan mendukung kebencian tersebut dengan mengatasnamakan pembenaran ideologi. Akibatnya, ekspresi tersebut dianggap oleh mereka sebagai pembenaran dalam pemahaman mereka (Martin \& Munoz, 2010).

Berbagai penelitian yang menjadikan media online telah banyak dilakukan. Salah satunya adalah analisis propaganda CNN terhadap masyarakat Amerika Serikat tentang Al-Qaeda. Penelitian ini menjelaskan bahwa media barata tersebut melaksanakan berbagai bentuk propaganda seperti teknik name calling, card stacking, dan testimonial. Hasilnya adalah terjadinya Islamofobia dan terciptanya mindset dikalangan masyarakat AS terhadap penduduk Arab dan Muslim, tahap ini adalah tahap dimana masyarakat sudah meyakini pendapat dan kebenarannya, yaitu banyaknya terjadi tindakan kekerasan dan diskriminasi dikalangan masyarakatnya yang dipengaruhi oleh propaganda media seperti CNN serta sikap pemerintah AS dalam melaksanakan implementasi kebijakan war on terror (Amalia, 2015). Disamping itu, penelitian terkait kekuasaan media massa dalam penggunaan terminology dalam menyampaikan berita. Penelitian tersebut menjelaskan bahwa menjadi hal yang penting sebuah media dalam melakukan manipulasi untuk mempengaruhi masyarakat dan peran penting stakeholder dalam membentuk kekuatan media sehingga menjadi sorotan publik (Quraisy, 2006).

Penelitian ini bertujuan mengetahui bagaimana media online melakukan konstruksi terhadap pemberitaan terkait Islaimc State of Iraq and Syria (ISIS).

\section{BAHAN DAN METODE Rancangan Penelitian}

Pada penelitian ini, peneliti melakukan penelitian analisis framing dengan tipe penelitian analisis kualitatif, dimana peneliti berusaha mendeskripsikan konstruksi pemberitaan tentang ISIS dalam media online Al Jazeera.com, CNN.com, Kompas.com dan Republika.co.id yang telah menimbulkan stigma Islamofobia di masyarakat. Pendekatan kualitatif yang dimaksud disini cenderung pada kualitas data, dan bukan pada kuantitas data yang dianalisis.

\section{Objek Penelitian}

Objek penelitian dilakukan baik secara online maupun secara offline dalam bentuk hasil unduhan. Pemilihan media online Al Jazeera.com, CNN.com, Kompas.com dan Republika.co.id sebagai Objek penelitian didasarkan pada fakta bahwa keempat media online tersebut banyak memposting berita tentang ISIS

\section{Sumber Data dan Teknik Pengumpulan Data}

Dalam penelitian ini, sampel diambil secara purposive Sampling, yakni peneliti secara sengaja memilih sampel sesuai dengan periode tertentu atas dasar pertimbangan kuat dari peneliti. Sumber data utama peneliti adalah berita dari portal online Al Jazeera.com, CNN.com, Kompas.com dan Republika.co.id. Baik berupa teks maupun foto dan gambar. Berita yang dimaksud adalah berita tentang Islamic State of Iraq and Syria (ISIS) yang terdapat pada keempat portal berita online yang telah disebutkan.

\section{Analisis Data}

Teknik analisa yang digunakan penulis adalah teknis analisis framing dengan menggunakan model analisis Zhongdang Pan dan Gerald M. Kosicki. Analisis data dalam 
penelitian berupa seleksi data, reduksi data, dan analisis (Sobur, 2002).

\section{HASIL}

\section{Profil Islamic State of Iraq and Syria (ISIS)}

Kelompok ini awalnya didirikan dengan nama Jama'at al-Tawhid wal-Jihad pada tahun 1999, lalu bergabung dengan al-Qaeda pada tahun 2004. Kelompok ini terlibat pemberontakan Irak setelah pasukan koalisi Barat menyerbu Irak tahun 2003. Bulan Januari 2006, kelompok tersebut bergabung dengan grup-grup pemberontak Sunni yang tergabung dalam Dewan Syura Mujahidin. Mereka memproklamasikan pemberntukan Negara Islam Irak (NII) pada bulan Oktober 2006. Setelah Perang Saudara Suriah pecah bulan Maret 2011, NII di bawah kepemimpinan al-Baghdadi mengutus para pejuang ke Suriah pada Agustus 2011. Para pejuang tersebut menyebut dirinya Jabhat an-Nușrah li-Ahli asy-Syām-Front alNusra-dan menguasai daerah-daerah yang mayoritas dihuni warga Sunni di kegubernuran Ar-Raqqah, Idlib, Deir ez-Zor, dan Aleppo. Bulan April 2013, al-Baghdadi mengumumkan penyatuan NII dengan Front al-Nusra dan nama barunya, Negara Islam Irak dan Syam (NIIS). Namun demikian, Abu Mohammad al-Julani dan Ayman al-Zawahiri, masing-masing pemimpin al-Nusra dan al-Qaeda, menolak penyatuan tersebut. Setelah perebutan kekuasaan selama delapan bulan, al-Qaeda memutus semua hubungan dengan NIIS pada tanggal 3 Februari 2014 karena NIIS enggan berunding dan "luar biasa keras kepala". Di Suriah, kelompok ini melancarkan serangan darat terhadap pasukan pemerintah dan faksi pemberontak dalam Perang Saudara Suriah. Mereka mulai dikenal luas setelah mendesak mundur pasukan pemerintah Irak dari kota-kota besar di Irak barat dalam sebuah serangan pada awal 2014. Hilangnya kendali Irak atas wilayahnya sendiri mengakibatkan pecahnya pemerintahan Irak dan memicu aksi militer Amerika Serikat di Irak.

NIIS mahir memanfaatkan media sosial. Mereka mengepos video-video pemenggalan tentara, warga sipil, wartawan, dan pekerja sosial di Internet dan dikenal karena menghancurkan situs-situs warisan budaya. Para tokoh Muslim di seluruh dunia mengutuk ideologi dan aksi-aksi NIIS; mereka berpendapat bahwa kelompok tersebut sudah keluar jauh dari ajaran Islam yang sejati dan segala tindakannya tidak mencerminkan ajaran atau nilai-nilai yang dibawa agama ini. Penggunaan nama "Negara Islam" dan konsep kekhalifahan oleh kelompok ini dikritik secara luas. PBB, NATO, berbagai negara, dan sejumlah kelompok Muslim besar menolak keduanya.

\section{AlJazeera.com}

Tabel 1 memperlihatkan hasil analisis framing pada portal media online AlJazeera.com yang menjadi sampel penelitian. Dari Hasil framing menunjukkan bahwa berdasarkan struktur Sintaksis portal Aljazeera dalam menulis artikel, penulis pada portal tersebut melengkapi kutipan berdasarkan narasumber, tetapi dalam menuangkan ide dalam sebuah artikel berita cenderung menggunakan analisa dan pengaman pribadi dari penulis. Dalam unsur Skrip, karena ketidaklengkapan salah satu unsure $5 \mathrm{~W}+1 \mathrm{H}$, maka dalam beberapa artikel sulit untuk diidentifikasi kapan persitiwa dalam berita terjadi. Dalam hal pemilihan tema, didominasi dengan gambaran kehidupan kaum Muslim di Amerika dan Eropa setelah terjadinya peningkatan Islamofobia dengan maraknya pemberitaa terkait ISIS di berbagai media.

\section{CNN.com}

Tabel 2 mendeskripsikan bahwa berdasarkan struktur sintaksis beberapa artikel pada portal CNN.com, penulis dalam portal media tersebut beberapa kali menjadikan dokumen tunggal sebagai referensi dan sumber pemberitaan, bahkan mengutip narasumber tunggal dalam beberapa pemberitaanya tanpa melakukan konfirmasi sehingga berita yang disajikan kepada pembaca menjadi tidak berimbang. Kelebihan dari portal CNN.com adalah penulis dalam poertal ini, selalu melengkapi unsur Skrip dalam menulis berita walaupun tidak dijelaskan secara detail dan mendalam. Berdasarkan struktur tematik terlihat bahwa portal berusaha merangkai berita dengan runut, sehingga pembaca mampu memahami pesan yang ingin disampaikan kepada seluruh pembacanya. Penekanan terhadap isu yang diagendakan olen portal CNN.com sangat terlihat jelas dari sudut pandang retoris pada portal ini. Penggunaan beberapa istilah, 
pemuatan foto, grafik bahkan video disetting oleh media sehingga dengan mudah pesan bisa sampai kepada masyarakat.

\section{Kompas.com}

Tabel 3 memperlihatkan bahwa Kompas.com dalam merangkai sebuah berita selalu menghadirkan narasumber yang utuh, namun berdasarkan struktur Sintaksis terlihat bahwa portal ini seringkali juga menggunakan analisa pribadi. Ketiadanyaa beberapa unsur 5W $+1 \mathrm{H}$ dalam berita menyebabkan informasi dalam portal menjadi tidak utuh. Dari sisi tematik, Kompas.com dalam pemilihan tema terlihat lebih berimbang dengan mengaitkan posisi ISIS di dunia barat dan dampak yang ditimbulkan serta peluang berkembangan ISIS di Indonesia. Secara Retoris, Portal Kompas.com menggunakan penekanan berita dengan menyertakan istilah-sitilah yang memperkuat argumentasi dalam berita serta memuat beberapa foto.

\section{Republika.co.id}

Tabel 4 menunjukkan dari sisi sintaksis bahwa mayoritas berita yang disajikan dalam portal Republika.com hanya mengutip satu narasumber, bahkan ada artikel yang ditulis hanya untuk menganalisa pernyataan seorang narasumber. Penulis dalam portal ini, banyak menjadikan berita internasional sebagai rujukan, sehingga kemurnian narasumber sulit terkonfirmasi. Unsur $5 \mathrm{~W}+1 \mathrm{H}$ yang harus dimiliki oleh setaip berita belum dilengkapi oleh portal ini, peneliti menemukan beberapa artikel tidak melengkapi beberapa unsure skrip dalam menulis artikelnya. Secara tematik, penulis dalam portal ini menulis berita dengan tendensi media yang kontra terhadap Amerika dan Barat. Hal ini Terlihat dari pemilihan judul dan topik berita. Penekanan retoris dalam portal lebih difokuskan pada penggunaan foto-foto.

\section{PEMBAHASAN}

Pada penelitian ini ditemukan bahwa konstruksi dan framing yang dilakukan oleh keempat media online menggambarkan pemberitaan ISIS berdasarkan sudut pandang dan ideologi sebuah media.

Dalam pemberitaan mengenai ISIS yang peneliti angkat menjadi sampel penelitian, media tidak dapat dilepaskan dari berbagai kepentingan politik dan ideologi. Kepentingan-kepentingan ini saling bersaing di balik polemik tersebut yang dapat menjadikan media tidak netral, jujur, adil dan objektif. Netralitas, kejujuran, dan objektivitas media menjadi "barang langka" jika berbenturan dengan berbagai kepentingan yang ada di balik media. (Muslich. 2008)

Konstruksi sosial adalah sebuah proses eksternalisasi, objektivasi, dan internalisasi yang terjadi antara individu di dalam masyarakat (Bungin, 2008). Ketiga proses tersebut terjadi secara simultan membentuk dialektika, serta menghasilkan realitas social berupa pengetahuan umum, konsep, kesadaran umum, dan wacana publik. Konstruksi sosial dibangun oleh individu dan masyarakat secara dialektika. Dan yang dimaksud dengan kontruksi sosial adalah realitas yang berupa realita objektif, subjektif, maupun simbolis (Hansen, 1991).

Konstruksi realitas media adalah cara mana yang dilakukan media dalam menginterpretasi dan mengkonstruksi sebuah realitas. Bagi kaum konstruksionis, sebuah media bukanlah entitas yang bebas nilai, ia dipengaruhi oleh berbagai faktor. Konstruksi realita yang dilakukan oleh media dapat dilihat dalam cara apa media membingkai isu (media framing) (Berger \& Thoman,1966). Mengikuti konsep sederhana tentang framing bahwa awak media melakukan seleski isu dan menonjolkan aspek tertentu dari realitas. Framing dipandang sebagai cara awak media menempatkan informasi-informasi dalam konteks yang khas sehingga isu tertentu mendapat alokasi lebih besar daripada isu lain (Etnman, 1993).

Berdasarkan keempat media yang dijadikan objek penelitian, media online $\mathrm{Al}$ Jazeera.com, CNN.com, Kompas.com, dan Republika.co.id memberikan porsi terhadap pemberitaan ISIS dalam berkontribusi terhadap terbentuknya stigma Islamofobia (Anti-Muslim) di masyarakat. Dari hasil penelitian, CNN.com sebagai sebuah media barat terlihat jelas memberikan porsi pemberitaan yang besar terkait ISIS. Pemberitaan dirangkai sedemikian rupa untuk mempengaruhi masyarakat bahwa ISIS dan Islam berasal dari induk yang sama. Kerangka pemberitaan yang digunakan oleh CNN.com tentu saja sangat berdasar, dimana media tersebut dimiliki oleh yahudi yang secara 
nyata dalam berbagai kondisi tidak pernah berpihak pada Islam.

Media online Al-Jazeera dalam melakukan framing berita ISIS menggunakan kacamata normatif. Beberapa berita yang dimuat dalam media tersebut menggambarkan kondisi diskriminatif yang dihadapi kaum Muslim sebagai imbas terhadap berbagai pemberitaan yang mengaitkan Islam dan ISIS. Media lokal seperti Kompas.com melakukan framing berita dengan lebih berimbang dari segi pemilihan isu, walau pada kenyataan artikel yang dimuat dalam portal tersebut masih mengandung opini pribadi dari penulisnya. Usaha yang berimbang yang dialkukan oleh Kompas.com tentu saja dengan alasan dan pertimbangan, mengingat media tersebut lahir dan besar di Negara yang didominasi kaum muslim, jadi secara tidak langsung ketika memberitakan Islam secara vulgar, maka akan menemui berbagai reaksi dari kalangan Muslim. Sedangkan, Portal Republika.co.id, media yang hadir sebagai media representasi kaum muslim di Indonesia dalam mengemas berita secara eksplisit memprovokasi masyarakat untuk anti Amerika dan dunia barat. Republika mengemas berita dengan mengkonstruksinya dengan sangat dramatis sehingga pembaca akan terpengaruh bahwa Barat memiliki kebencian kepada Muslim karena agama mereka (Eriyanto, 2002).

\section{KESIMPULAN DAN SARAN}

Hasil analisis dari penelitian ini dapat ditarik beberapa kesimpulan, antara lain; CNN.com sebagai media barat merepresentasikan diri dalam pemberitaan bahwa media tersebut sangat tidak pro terhadap Islam, dengan mengaitkan Islam dan ISIS dalam berbagai kesempatan, sedangkan AlJazeera.com yang lahir untuk mengkounter berbagai pemberitaan yang menyudutkan Islam, lewat pemberitaanya mencoba membuka mata dunia bahwa barat (Amerika dan Eropa) melakukan tindakan diskriminatif terhadap Muslim. Kompas.com sebagai media yang lahir di negara mayoritas muslim degan hati-hati mengangkat isu tersebut dan mengesankan kepada pembaca sebagai media yang berimbang. Sedangkan, Republika.co.id mengemas berita dengan mengkonstruksinya sehingga pembaca akan terpengaruh bahwa Barat memiliki kebencian kepada Muslim karena agama mereka. Berdasarkan hasil penelitian yang telah dilakukan oleh peneliti, maka ada beberapa saran yang peneliti sertakan untuk sebagai acuan penelitian selanjutnya yang serupa: agar masyarakat lebih jeli dalam memilah dan memilih berita dan lebih kritis dalam memaknai pesan yang disampaikan dalam suatu berita. Pengaruh yang diterima media kadang membuat pergeseran makna yang mestinya disadari dengan baik oleh masyarakat. dan bagi media, baik media massa ataupun media online, seharusnya berbenah diri untuk kembali kepada asas utama sebuah berita yanitu kebenaran dan objektivitas (Truth and Objectivity).

\section{DAFTAR PUSTAKA}

\section{Amalia A. (2015). Analisis Propaganda CNN (Cable News Network) terhadap Masyarakat Amerika Serikat tentang Al- Qaeda. E-Journal Ilmu Hubungan Internasional, 3 (3): 521-532}

Berger P.L. \& Thomas L. (1966). The Social Construction of Reality; Treatise in the Social of knowledge. Anchor Books Doubledasy \&Company.Inc. Newyork: Garden City.

Bungin B. (2008). Konstruksi Sosial Media Massa, Kekuatan Pengaruh Media, Iklan Televisi, dan Keputusan Konsumen serta Kritik terhadap Peter L.Berger dan Thomas Luckmann. Jakarta: Kencana Prenada Media Grup.

Eriyanto (2002). Analisis Framing: Konstruksi, Ideologi, dan Politik Media. Yokyakarta: LKIS

Hansen A. (1991). The Media and the Social Construction of the Environment. Media, Culture and Society. SAGE Vol. 13, 443458

Entman R.N. (1993). Framing: Toward Clarification of Fractured Paradigm. Journal of Communication vol. 43. International Communication Association. $8: 51-58$

Martin G. \& Munoz. (2010). Unconsious Islamophobia. Human Architecture: 
Journal of the Sociology of SelfKnowledge VIII, 2, FALL 2010, 21-28.

McQuail D. (2000). Mass Communication Theory. California: SAGE Publication ltd.

Mubarak M.Z. (2015). Dari NII ke ISISTransformasi Ideologi dan Gerakan dalam Islam Radikal di Indonesia Kontemporer. Episteme Jurnal, 10: 77-89.

Mubarok \& Made D. A. (2012). Konstruksi Pemberitaan Media Tentang Negara Islam Indonesia (Analisis Framing Republika dan Kompas). Jurnal Ilmiah Komunikasi MAKNA, (3) 25-41.

Mulkan D. (2011). Dampak Pemberitaan Media. Pikiran Rakyat, Februari 18; Opini hal. 20.

Muslich M. (2008). Kekuasaan Media Massa Mengontruksi Realitas. Bahasa dan Seni, Tahun 36, Nomor 2, (9):150-159.

Sheehi S. (2011). Islamophobia: The Ideological Campaign against Muslim.Clarity Press, INC

Sobur A. (2002). Analisis teks media: suatu pengantar untuk analisis wacana, analisis semiotic, dan analisis framing. Bandung: PT Remaja Rosdakarya.

Susilo M. (2015). Serangan anti-Muslim di Inggris naik 300\% setelah kejadian Paris. Diakses 12 Desember 2015. Available from: http://www.bbc.com/indonesia/dunia/201 5/11/151125_dunia_inggris_antimuslim.

Quraishy B. (2006). Islamic Images and Terminology Used In the Western Media. Jurnal Medistor vol. 6. Dirjen Dikti, (13): 67-74. 
Tabel 1 Analisis Framing Pan dan Konsikci pada Portal AlJazeera.com

\begin{tabular}{cl}
\hline Framing & \multicolumn{1}{c}{ Hasil Analisis } \\
\hline Sintaksis & $\begin{array}{l}\text { Artikel berita lengkap berisi kutipan dari narasumber, tetapi dalam menuangkan ide pada berita, } \\
\text { penulis dalam portal cenderung menggunakan analisa pribadi, bahkan dalam salah satu artikel } \\
\text { peneliti menemukan sebuah berita yang dibangun dengan mengutip narasumber tunggal. }\end{array}$ \\
& $\begin{array}{l}\text { Dalam salah satu artikel tidak dijelaskan unsur When, sehingga pembaca sulit untuk } \\
\text { mengkonfirmasi kapan peristiwa terjadi. }\end{array}$ \\
Skrip & $\begin{array}{l}\text { Pemilihan TEMA, Portal menyajikan berita yang didominasi dengan gambaran kondisi kaum } \\
\text { Tematik }\end{array}$ \\
& $\begin{array}{l}\text { Muslim di Amerika dan Eropa sebagai akibat meningkatnya gelombang ISLAMOFOBIA yang } \\
\text { merupakan imbas pemberitaan ISIS dikaitkan dengan ISLAM }\end{array}$ \\
Retoris & $\begin{array}{l}\text { Penegasan dalam artikel terlihat dari penekanan foto dan beberapa istilah; "clear uptick in anti } \\
\text { Islam", "Islamic Caliphate", dan "New Assasins" }\end{array}$ \\
\hline
\end{tabular}

Tabel 2Analisis Framing Pan dan Konsikci pada Portal CNN.com

\begin{tabular}{cl}
\hline Framing & \multicolumn{1}{c}{ Hasil Analisis } \\
\hline Sintaksis & $\begin{array}{l}\text { Dalam salah satu artikel penulis hanya menjadikan bocoran dokumen Edward Snowden } \\
\text { menjadika rujukan berita. Beberapa artikel hanya mengutip satu narasumber dan tidak } \\
\text { mengkonfirmasi pemberitan, jadi terlihat berita yang disajikan tidak berimbang. }\end{array}$ \\
Skrip & Unsur 5W + 1H lengkap walau tidak terlalu detail. \\
Tematik & $\begin{array}{l}\text { Penulis CNN.com merangkai berita dengan runut, sehingga pembaca mampu memahami pesan } \\
\text { yang diagendakan oleh Media. }\end{array}$ \\
Retoris & $\begin{array}{l}\text { Penekanan terhadap apa yang diagendakan oleh Media, dikuatkan dengan memuat foto, grafik } \\
\text { dan video. Penulis dalam portal juga menegaskannya dengan mengutip beberapa istilah; }\end{array}$ \\
& "Islamization of America" dan "Toxic Hate". \\
\hline
\end{tabular}

Tabel 3 Analisis Framing Pan dan Konsikci pada Portal Kompas.com

\begin{tabular}{|c|c|}
\hline Framing & Hasil Analisis \\
\hline Sintaksis & $\begin{array}{l}\text { Seluruh artikel dalam media, dilengkapi penulis dengan menyertakan kutipan narasumber, tetapi } \\
\text { penulis masih menggunakan analisa pribadi untuk memperkuat artikel. } \\
\text { Unsur how pada salah satu artikel tidak disertakan }\end{array}$ \\
\hline Skrip & $\begin{array}{l}\text { Pemilihan tema lebih berimbang dengan mengaitkan posisi ISIS dengan dunia barat dan } \\
\text { imbasnya terhadap Indonesia dan peluang berkembanganya ISIS di Indonesia. }\end{array}$ \\
\hline Tematio & $\begin{array}{l}\text { Penggunaan istilah: "ISIS is Closed", "mereka dan kita", "ideologi ekstrimis" dan "khilafah } \\
\text { jauh" diguanakan untuk memperkuat argumentasi penulis. }\end{array}$ \\
\hline Ketoris & $\begin{array}{l}\text { Penulis menggunakan foto untuk mendukung artikel, walau keotentikan foto belum } \\
\text { terkonfirmasi }\end{array}$ \\
\hline
\end{tabular}


Tabel 4Analisis Framing Pan dan Konsikci pada Portal Republika.co.id

Framing Hasil Analisis

Sintaksis Mayoritas berita yang disajikan hanya mengutip satu narasumber, bahkan ada artikel yang ditulis untuk menganalisa pernyataan seorang narasumber. Penulis dalam protel ini, banyak menjadikan berita internasional sebagai rujukan, sehinggan kemurnian narasumber sulit terkonfirmasi.

Skrip Unsur when tidak mengkapi $5 \mathrm{~W}+1 \mathrm{H}$ yang seharusnya wajib dimiliki sebuah berita.

Tematik Terlihat dari pemilihan sjudul dan topik berita, ada tendensi media yang kontra terhadap Amerika dan Barat.

Retoris Penekanan dalam portal diungkapkan langsung dalam artikel,tetapi beberapa artikel tidak disertai dengan foto 